Received Date : 13-Nov-2015

Revised Date : 26-Jan-2016

Accepted Date : 01-Mar-2016

Article type : Original Papers

\title{
Prognostic significance of pulsatile tinnitus in cervical artery dissection
}

Lars Kellert ${ }^{\mathrm{a},{ }^{*}}$, MD; Manja Kloss ${ }^{\mathrm{a}^{*}}$, MD; Alessandro Pezzini ${ }^{\mathrm{c}}$, MD; Stéphanie Debette $\mathrm{e}^{\mathrm{e}, \mathrm{f}, \mathrm{g}}$, PhD; Didier Leys ${ }^{\mathrm{f}}, \mathrm{PhD}$; Valeria Caso ${ }^{\mathrm{h}}, \mathrm{PhD}$; Vincent N. Thijs ${ }^{\mathrm{i}, \mathrm{j}}, \mathrm{PhD}$; Anna Bersano ${ }^{\mathrm{k}}, \mathrm{PhD}$; Emmanuel Touzé ${ }^{1}$ PhD; Turgut Tatlisumak ${ }^{\mathrm{d}, \mathrm{m}}, \mathrm{PhD}$; Christopher Traenka ${ }^{\mathrm{n}}, \mathrm{MD}$; Philippe A. Lyrer $^{\mathrm{n}}$, MD; Stefan T. Engelter ${ }^{\mathrm{n}, \mathrm{o}}$, MD; Tiina M. Metso ${ }^{\mathrm{d}}, \mathrm{PhD}^{*}$; and Caspar GrondGinsbach $^{\mathrm{a}}, \mathrm{PhD}^{*}$; for the Cervical Artery Dissection and Ischemic Stroke Patients (CADISP)Study Group

*These authors contributed equally.

${ }^{a}$ Department of Neurology, Heidelberg University Hospital, Heidelberg, Germany;

${ }^{b}$ Department of Neurology, University Hospital, Ludwig-Maximilians University Munich, Germany; 'Department of Clinical and Experimental Sciences, Neurology Clinic, University of Brescia, Brescia, Italy; ${ }^{d}$ Department of Neurology, Helsinki University Central Hospital, Helsinki, Finland ; Department of Neurology, Hôpital Lariboisière, Paris, France; ${ }^{f}$ Department of Neurology, University Lille Nord de France, INSERM U 1171, Lille, France; ${ }^{g}$ Department of Epidemiology and Public Health, INSERM U744, Pasteur Institute, Lille, France; ${ }^{h}$ Stroke Unit, Perugia University Hospital, Perugia, Italy; ${ }^{i}$ KU Leuven - University of Leuven, Department of Neurosciences, VIB - Vesalius Research Center, Experimental Neurology - Laboratory of Neurobiology, Leuven, Belgium; ${ }^{j}$ Neurology, University Hospitals Leuven, Leuven, Belgium; ${ }^{k}$ Cerebrovascular Unit IRCCS Foundation C.Besta Neurological Institute, via Celoria 11, Milan, Italy; 'University of Caen Basse Normandie, INSERM U919, Department of Neurology, CHU Côte de Nacre, Caen, France; ${ }^{m}$ Institute of Neuroscience and This is the author manuscript accepted for publication and has undergone full peer review but has not been through the copyediting, typesetting, pagination and proofreading process, which may lead to differences between this version and the Version of Record. Please cite this article as doi: $10.1111 /$ ene.13031

This article is protected by copyright. All rights reserved 
Physiology, Sahlgrenska Academy at University of Gothenburg, Gothenburg, Sweden and Department of Neurology, Sahlgrenska University Hospital, Gothenburg, Sweden; ${ }^{n}$ Department of Neurology, Basel University Hospital, Basel, Switzerland; ${ }^{o}$ Neurorehabilitation Unit, University Center for Medicine of Aging and Rehabilitation, Felix Platter Hospital, Basel, Switzerland.

\section{Corresponding author:}

Lars Kellert, Department of Neurology, Ludwig-Maximilians-University Munich, Marchioninistrasse 15, 81377 Munich, Germany, Phone: 0049894400 73692, Fax: 004989 4400 76775,Lars.Kellert@med.uni-muenchen.de

Running title: Pulsatile Tinnitus and cervical artery dissection

Keywords: Cervical artery dissection, pulsatile tinnitus, acute ischemic stroke, outcome

$\dagger$ Appendix: CADISP (Cervical Artery Dissections and Ischemic Stroke Patients) Coinvestigators

\section{Abstract:}

Background and purpose: To investigate whether pulsatile tinnitus (PT) in cervical artery dissection (CeAD) has prognostic significance.

Methods: All CeAD patients from the CADISP (Cervical Artery Dissection and Ischemic Stroke Patients) study with documentation of PT were analyzed. The presence of PT was systematically assessed using a standardized questionnaire. Stroke severity at admission was defined according to the National Institutes of Health Stroke Scale (NIHSS). Excellent outcome after 3 months was defined as modified Rankin Scale (mRS) of 0 to 1.

Results: 63 of 778 patients $(8.1 \%)$ reported PT. PT+patients presented less often with ischemic stroke $(41.3 \%$ vs. $63.9 \%, p<0.001)$, more often with dissection in the internal carotid artery $(85.7 \%$ vs. $64.2 \%, p=0.001)$, less often with vessel occlusion $(19.0 \%$ vs. $34.1 \%$, $\mathrm{p}=0.017)$ and more often with excellent outcome at 3 months $(92.1 \%$ vs. $75.4 \%, p=0.002)$. Logistic regression analysis identified PT as an independent predictor of excellent outcome after 3 months (OR 3.96, 95\%CI 1.22-12.87) adjusted to significant outcome predictors NIHSS on admission (OR 0.82, 95\%CI 0.79-0.86), Horner syndrome (OR 1.95, 95\%CI 1.163.29), and vessel occlusion (OR 0.62, 95\%CI 0.40-0.94) and to non-significant predictors age, sex, pain and location of CeAD. 
Conclusion: Presence of PT in CeAD is associated with benign clinical course and predicts favourable outcome.

\section{Introduction:}

Cervical artery dissection (CeAD) is a major cause of stroke in young and middle-aged patients, responsible for up to $25 \%$ of ischemic strokes. Besides stroke, CeAD presents with local signs that might occur solely or in addition to stroke symptoms. Local signs include headache, neck pain, Horner syndrome, cranial nerve palsy, cervical-root injury, and pulsatile tinnitus (PT) ${ }^{(1-3)}$. PT has been observed in about 5-15\% of CeAD-patients, perhaps favoring female sex ${ }^{(4-6)}$. Dissections in the carotid system are about three-times more often associated with PT than dissections in the vertebral artery system ${ }^{(4)}$. Different causes can lead to blood flow accelerations and local turbulence that may result in the perception of PT. The most probable reason for PT upon CeAD is higher grade stenosis of the affected artery $(7,8)$. Here, we analyzed patients from the CADISP (Cervical Artery Dissection and Ischemic Stroke Patients) Study to investigate whether PT has prognostic significance in CeAD patients.

\section{Methods:}

The CADISP consortium enrolled 983 CeAD patients in 18 neurological centers in 8 countries, both prospectively and retrospectively (for more details see ${ }^{(9,10)}$ ). At study entry, detailed signs and symptoms of each participant were recorded using a standardized questionnaire $^{(10)}$. This questionnaire included the variable "presence or absence of PT", which was used for the current study. PT was defined as the experience of perceiving sounds without any known audible external sound, coinciding with the patient's heartbeat lasting for more than 5 minutes ${ }^{(11,12)}$. Stroke severity on admission was assessed with the National Institutes of Health Stroke Scale (NIHSS). For patients without ischemia, a dummy value of NIHSS on admission $=0$ was set, as well as for patients without stroke but with transient ischemic attack with missing NIHSS value. Outcome at 3 months was defined as excellent if modified Rankin Scale (mRS) was 0-1. Vessel occlusion was detected via contrast enhanced magnetic resonance angiography (MRA), computed tomography angiography (CTA), or ultrasound or using a combination of them. The parameter pain included both neck pain and headache. In the current study we included patients with reported presence or absence of PT and with documentation of stroke severity on admission and functional outcome at 3 months. One patient with dissection of the common carotid artery was excluded. 


\section{Statistical analysis}

PT+patients were compared with PT-patients. Normally distributed data were presented as mean and standard deviation (SD), non-normally distributed data as median and range. For categorical variables, counts and percentages were given. Data were compared with Student's T-test, Mann-Whitney-U test, or Fisher exact Test where appropriate. Logistic regression analysis was used to analyze the association between PT and outcome after adjustment for age, sex, NIHSS, Horner syndrome, pain, location of the dissection and vessel occlusion. Because NIHSS and stroke both reflect ischemic infarction and both are significantly different according to PT, only NIHSS was used for further analysis due to additional information of stroke severity. Crude odds ratios (OR) with 95\%-confidence intervals (95\%-CI) and OR adjusted to potential confounders were calculated. A two-sided p-value of $<0.05$ was considered as statistically significant. Statistical analysis was performed with Statistical Package for the Social Sciences, SPSS (SPSS Inc., 23.0 for Windows).

\section{Ethics}

The CADISP-study protocol (http://clinicaltrials.gov/ct2/show/NCT00657969) was approved by competent local authorities of all participating centers and is conducted according to the national rules concerning ethics committee approval and informed consent.

\section{Results:}

Seven hundred seventy-eight CeAD patients with documented information about PT, NIHSS and mRS at 3 month comprised the final study sample. 63 patients $(8.1 \%)$ reported PT (PT+patients), 29 of 311 (9.3\%) prospectively enrolled patients and 34 of 467 (7.3\%) retrospectively enrolled patients $(p=0.348)$. PT+patients were more likely to be female $(65.1 \%$ vs. $41.6 \%, p<0.001)$, and were less likely to present with ischemic stroke $(41.3 \%$ vs. $63.9 \%, p=0.001)$. Among the PT+patients, 54 (77.8\%) had dissections in the internal carotid artery (ICA), compared to $459(60.6 \%)$ of the PT-patients $(p=0.001)$. Moreover, 5 patients (7.9\%) in the PT+group and 26 patients (3.6\%) in the PT-group had dissections in both ICA and VA. Thus the total proportions of ICAD were $85.7 \%$ and $64.2 \%(p=0.001)$, respectively. Occlusion was less frequent in PT+patients than in PT-patients (19.0\% vs. 34.1\%, $p=0.017)$. Median mRS after 3 months was 0 in PT+patients vs. 1 in PT-patients $(p=0.016)$. Excellent outcome after 3 months favored PT $(92.1 \%$, vs. $75.4 \%, p=0.002)$. The rate of recurrent stroke was low and not different between PT- and PT+ groups (15 (2.1\%) vs. 0, p=0.627) (Table 1). 
Logistic regression analysis identified PT as a predictor for excellent outcome after 3 months (odds ratio $=3.96,95 \%$ confidence interval $=1.22-12.87)$. The association between PT and outcome was independent from other significant outcome predictors such as NIHSS on admission (OR 0.82, 95\%CI 0.79-0.86), Horner syndrome (OR 1.95, 95\%CI 1.16-3.29), and vessel occlusion (OR 0.62, 95\% CI 0.40-0.94) and from non-significant predictors such as age (OR 0.98, 95\%CI 0.96-1.00), male sex (OR 1.45, 95\%CI 0.94-2.24), pain (OR 0.91, 95\%CI 0.53-1.55) and location of CeAD (Table 2).

\section{Discussion:}

In this study PT was associated with a favorable outcome in patients with CeAD. PT+patients had an almost 4-fold increased likelihood of an excellent outcome compared to those without PT. Presence of PT was also associated with female sex, lower likelihood of stroke, fewer arterial occlusions and fewer dissections in the vertebral artery. Logistic regression analysis showed PT to be an independent predictor for excellent outcome adjusted to age, sex, NIHSS, Horner syndrome, pain, vessel occlusion and location of CeAD.

In this study we focused on easily assessable clinical parameters (age, sex, NIHSS, Horner syndrome, pain, and PT) to allow treating physician to gain a quick overview of patients characteristics which might be associated with more benign course. As recently reported for Horner syndrome, $\mathrm{PT}$ is associated with a more benign clinical course of $\mathrm{CeAD}^{(13)}$. Our study did not attempt to discover the mechanism behind PT in CeAD, but rather describing authentic clinical situation in those patients.

Although PT is less frequently reported than other local signs such as pain or Horner syndrome, it was not rare, being reported by $8.1 \%$ of our patients. Because PT predicts favourable outcome, it should be of interest and physicians should specifically ask for its presence. Underlying cause of a newly occurred PT is in up to $20 \%$ cervical artery stenosis or aneurysm $^{(8,14)}$. Thus a newly occurred PT should lead clinical and vascular examination to exclude underlying CeAD. PT was the only clinical sign of CeAD in three of our patients. In addition, a newly occurred PT in the course of CeAD might indicate changes in vessel status like revascularization of an occlusion or vice versa. In our analysis PT predicted favourable outcome independent of vessel occlusion. This might be surprising because PT is supposed to be related to vessel status, especially to high grade stenosis. One could therefore speculate that PT might be a surrogate of non-occlusion of the affected vessel and this fact drives the association of PT and favourable outcome. But this could not be excluded or confirmed by our data. It is not known in how many tinnitus patients the vessel status (occlusion/stenosis of 
various degrees) was the same 1) at the time of vascular imaging and 2) at the time of occurrence of tinnitus; the time course of PT was not recorded. Thus for example late occurrence or disappearance in the course of PT could not be analysed. This is the main limitation of our study. The prognostic significance of PT is not yet understood and the interpretation remains speculative.

Another major limitation of our study is the lack of information about the degree and the detailed location (i.e. arterial segment) of the stenosis. Comparing retrospectively and prospectively included CeAD patients PT reporting was within the same range of 7-9\%. This might indicate that selection bias in reporting PT is not crucial. However, we cannot exclude underreporting of PT in severely affected patients.

\section{Conclusion:}

Presence of PT in CeAD is associated with a benign clinical course with lower probability of stroke, less severe strokes, and better outcome at 3-month.

\section{Funding: none}

\section{Disclosures:}

LK, MK, AP, SD, DL, TT, CT report no disclosures.

TMM has received funding from the Finnish Medical Foundation, Helsinki University Central Hospital Research Fund, Helsinki University Medical Foundation, Orion Farmos Research Foundation, Päivikki and Sakari Sohlberg Foundation, Maire Taponen Foundation, the Lilly Foundation, Paavo Ilmari Ahvenainen Foundation, Aarne and Aili Turunen Foundation, Aarne Koskelo Foundation, the Maud Kuistila Memorial Foundation, Emil Aaltonen Foundation, Finnish Brain Foundation, and Alfred Kordelin Foundation.

VC has served as speaker for Boehringer Ingelheim, Sanofi, and Pfizer

VNT has received funding for travel or speaker honoraria from Bayer, Boehringer Ingelheim, Pfizer Inc and Medtronic; he has served on scientific advisory boards for Shire, Bayer, Pfizer and Boehringer Ingelheim and on the editorial board of Stroke. He is an associate editor of Acta Neurologica Belgica. He has received honoraria for being on the steering committee of the AX200 trial (SYGNIS). He has received research support from FWO Flanders.

$\mathrm{AB}$ has received funding for travel and congresses participations from Shire, Boehringer Ingelheim, and Sanofi-aventis. 
ET has served on scientific advisory boards for Bayer Schering Pharma, Pfizer, BMS, and Shire; has received speaker honoraria from Boehringer Ingelheim, Bayer Schering Pharma, Pfizer, BMS, and Shire; has received funding for travel from Astra Zeneca and BMS; he serves as assistant editor for Stroke; and has received research support from the French Ministry of Health.

PAL has served on scientific advisory boards for Bayer Schering Pharma, and Boehringer Ingelheim; has received funding for travel or speaker honoraria from Bayer Schering Pharma, Boehringer Ingelheim, and Shire plc; he serves as Co-Editor for Neurologie und Psychiatrie and on the editorial board of Swiss Archives of Neurology and Psychiatry; and has received research support from AstraZeneca, Boehringer Ingelheim, Sanofi-aventis, PhotoThera, the Swiss National Science Foundation, and the Swiss Heart Foundation.

STE has received funding for travel or speaker honoraria from Bayer, Boehringer Ingelheim,

Pfizer Inc, Sanofi-aventis, and Shire plc; he has served on scientific advisory boards for Bayer, Boehringer Ingelheim, Bristol-Meyer-Squibb, and Pfizer and on the editorial board of Stroke. He has received research support from the Kaethe-Zingg-Schwichtenberg-Fonds of the Swiss Academy of Medical Sciences, the Swiss Heart Foundation, and Swiss National Science Foundation.

\section{References:}

1. Debette S, Leys D. Cervical-artery dissections: predisposing factors, diagnosis, and outcome. The Lancet Neurology. 2009 Jul;8(7):668-78. PubMed PMID: 19539238.

2. Leys D, Lucas C, Gobert M, Deklunder G, Pruvo JP. Cervical artery dissections. European neurology. 1997;37(1):3-12. PubMed PMID: 9018025.

3. Sturzenegger M, Huber P. Cranial nerve palsies in spontaneous carotid artery dissection. Journal of neurology, neurosurgery, and psychiatry. 1993 Nov;56(11):1191-9. PubMed PMID: 8229030. Pubmed Central PMCID: 489820.

4. von Babo M, De Marchis GM, Sarikaya H, Stapf C, Buffon F, Fischer U, et al. Differences and similarities between spontaneous dissections of the internal carotid artery and the vertebral artery. Stroke; a journal of cerebral circulation. 2013 Jun;44(6):1537-42. PubMed PMID: 23632978.

5. Metso AJ, Metso TM, Debette S, Dallongeville J, Lyrer PA, Pezzini A, et al. Gender and cervical artery dissection. European journal of neurology : the official journal of 
the European Federation of Neurological Societies. 2012 Apr;19(4):594-602. PubMed PMID: 22150935.

6. Arnold M, Kappeler L, Georgiadis D, Berthet K, Keserue B, Bousser MG, et al. Gender differences in spontaneous cervical artery dissection. Neurology. 2006 Sep 26;67(6):1050-2. PubMed PMID: 17000975.

7. Baumgartner RW, Bogousslavsky J. Clinical manifestations of carotid dissection. Frontiers of neurology and neuroscience. 2005;20:70-6. PubMed PMID: 17290113.

8. De Ridder D, Menovsky T, Van de Heyning P. An otoneurosurgical approach to nonpulsatile and pulsatile tinnitus. B-Ent. 2007;3 Suppl 7:79-86. PubMed PMID: 18225613

9. Debette S, Metso TM, Pezzini A, Engelter ST, Leys D, Lyrer P, et al. CADISPgenetics: an International project searching for genetic risk factors of cervical artery dissections. International journal of stroke : official journal of the International Stroke Society. 2009 Jun;4(3):224-30. PubMed PMID: 19659826.

10. Debette S, Metso T, Pezzini A, Abboud S, Metso A, Leys D, et al. Association of vascular risk factors with cervical artery dissection and ischemic stroke in young adults. Circulation. 2011 Apr 12;123(14):1537-44. PubMed PMID: 21444882.

11. McCormack A, Edmondson-Jones M, Fortnum H, Dawes PD, Middleton H, Munro $\mathrm{KJ}$, et al. Investigating the association between tinnitus severity and symptoms of depression and anxiety, while controlling for neuroticism, in a large middle-aged UK population. International journal of audiology. 2015 Mar 13:1-6. PubMed PMID: 25766493.

12. Henry JA, Dennis KC, Schechter MA. General review of tinnitus: prevalence, mechanisms, effects, and management. Journal of speech, language, and hearing research : JSLHR. 2005 Oct;48(5):1204-35. PubMed PMID: 16411806.

13. Lyrer PA, Brandt T, Metso TM, Metso AJ, Kloss M, Debette S, et al. Clinical import of Horner syndrome in internal carotid and vertebral artery dissection. Neurology. 2014 May 6;82(18):1653-9. PubMed PMID: 24727317. 
14. Hofmann E, Behr R, Neumann-Haefelin T, Schwager K. Pulsatile tinnitus: imaging and differential diagnosis. Deutsches Arzteblatt international. 2013 Jun;110(26):451-8. PubMed PMID: 23885280. Pubmed Central PMCID: 3719451.

Table 1. Patients` characteristics and outcome according to Pulsatile Tinnitus (PT)

\begin{tabular}{|l|l|l|l|}
\hline & no PT (n=715) & PT (n=63) & P \\
\hline Age (mean [SD]) & $44.2(10.2)$ & $44.8(9.3)$ & $0.66^{*}$ \\
\hline Female sex & $296(41.6 \%)$ & $41(65.1 \%)$ & $<0.001^{\dagger}$ \\
\hline Stroke & $457(63.9 \%)$ & $26(41.3 \%)$ & $0.001^{\dagger}$ \\
\hline TIA & $164(22.9 \%)$ & $17(27.0 \%)$ & $0.441^{\dagger}$ \\
\hline NIHSS on admission (median [range]) & $2[0-25]$ & $1[0-18]$ & $0.275^{\dagger}$ \\
\hline Purely local symptoms (no ischemia) & $148(20.7 \%)$ & $27(42.9 \%)$ & $<0.001^{\dagger}$ \\
\hline Pain (neck pain/headache) & $579(81.0 \%)$ & $53(84.1 \%)$ & $0.616^{\dagger}$ \\
\hline Horner Syndrome & $206(28.8 \%)$ & $24(38.1 \%)$ & $0.149^{\dagger}$ \\
\hline ICAD & $433(60.6 \%)$ & $49(77.8 \%)$ & $0.001^{\dagger}$ \\
\hline VAD & $256(35.8 \%)$ & $9(14.3 \%)$ & \\
\hline ICAD+VAD & $26(3.6 \%)$ & $5(7.9 \%)$ & \\
\hline Occlusion & $244(34.1 \%)$ & $12(19.0 \%)$ & $0.017^{\dagger}$ \\
\hline PT as the only symptom & n.a. & $3(4.8)$ & \\
\hline & & & 0.027 \\
\hline mRS 3 months (median [range]) & $1[0-5]$ & $0[0-3]$ & $0.016^{\dagger}$ \\
\hline Excellent outcome (mRS 0-1) & $539(75.4 \%)$ & $58(92.1 \%)$ & $0.002^{\dagger}$ \\
\hline Recurrent stroke & $15(2.1 \%)$ & 0 & 0.627 \\
\hline & & & \\
\hline
\end{tabular}

*Student's-T-Test; ${ }^{\dagger}$ Fisher's exact Test; ${ }^{\ddagger}$ Mann-Whitney-U-Test; NIHSS indicates National Institutes of Health Stroke Scale, TIA = transient ischemic attack, ICAD = internal carotid artery dissection, $\mathrm{VAD}=$ vertebral artery dissection, $\mathrm{mRS}=$ modified Rankin Scale. The analysis of NIHSS on admission was restricted to the subgroup of patients with ischemia.

Table 2. Logistic regression analysis with excellent outcome (mRS 0-1) as dependent variable 


\begin{tabular}{|l|l|l|l|}
\hline & OR & $95 \%$ CI & $\mathrm{p}$ \\
\hline Age & 0.98 & $0.96-1.00$ & 0.065 \\
\hline Male sex & 1.45 & $0.94-2.24$ & 0.115 \\
\hline NIHSS on admission & 0.82 & $0.79-0.86$ & $<0.001$ \\
\hline Pulsatile Tinnitus & 3.96 & $1.22-12.87$ & 0.026 \\
\hline Horner syndrome & 1.95 & $1.16-3.29$ & 0.012 \\
\hline Pain (Neck pain/headache) & 0.91 & $0.53-1.55$ & 0.722 \\
\hline Occlusion & 0.62 & $0.40-0.94$ & 0.025 \\
\hline Location (ICA vs. VA)* & 1.03 & $0.65-1.62$ & 0.957 \\
\hline
\end{tabular}

NIHSS indicates National Institutes of Health Stroke Scale; Location site of dissection; ICA internal carotid artery, VA vertebral artery (*patients with CeAD in both ICAD and VAD are not included in the regression analysis), OR odds ratio, and CI confidence interval. 


\section{$\dagger$ Appendix: CADISP (Cervical Artery Dissections and Ischemic Stroke Patients) Co- investigators.}

Massimo Pandolfo, MD PhD, Department of Neurology, Erasmus University Hospital, Brussels and Laboratory of Experimental Neurology, ULB, Brussels, Belgium; Marie Bodenant, MD, Department of Neurology, Lille University Hospital - EA1046, France; Fabien Louillet, MD and Jean-Louis Mas, MD PhD, Department of Neurology, Sainte-Anne University Hospital, Paris, France; Sandrine Deltour, MD and Anne Léger, MD, Department of Neurology, Pitié-Salpêtrière University Hospital, Paris, France; Sandrine Canaple, MD and Olivier Godefroy, MD PhD, Department of Neurology, Amiens University Hospital, France; Yannick Béjot, MD PhD, Department of Neurology, Dijon University Hospital, France; Thierry Moulin, MD PhD and Fabrice Vuillier, MD, Department of Neurology, Besançon University Hospital, France; Michael Dos Santos, MD, Department of Neurology, University Hospital of Ludwigshafen, Germany; Rainer Malik, MD PhD, Department of Neurology, University Hospital of Munich, Germany; Ingrid Hausser, PhD, Department of Dermatology, Heidelberg University Hospital, Germany; Tobias Brandt MD PhD, Constanze ThomasFeles, MD, Kliniken-Schmieder, Heidelberg, Germany, Ralf Weber, MD, Department of Neurology, SRH Kurpfalzkrankenhaus, Heidelberg, Germany; Paolo Costa, MD, Loris Poli, MD, Andrea Morotti, MD and Alessandro Padovani, MD PhD, Department of Neurology, Brescia University Hospital, Italy; Silvia Lanfranconi, MD and Pierluigi Baron, MD PhD, Department of Neurology, Milan University Hospital, Italy; Carlo Ferrarese, MD PhD, University of Milano Bicocca, San Gerardo Hospital, Monza, Italy; Giacomo Giacolone, MD, Milan Scientific Institute San Raffaele University Hospital, Italy; Stefano Paolucci, MD PhD, Department of Rehabilitation, Santa Lucia Hospital, Rome, Italy; Felix Fluri, MD, Florian Hatz, MD, Dominique Gisler, MD and Margareth Amort, MD, Department of Neurology, Basel University Hospital, Switzerland; Steve Bevan, PhD, Clinical Neuroscience, St George's University of London, UK; Ayse Altintas, MD PhD, Department of Neurology, University Hospital of Istanbul, Turkey

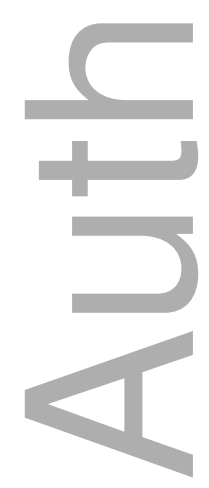

This article is protected by copyright. All rights reserved 


\section{University Library}

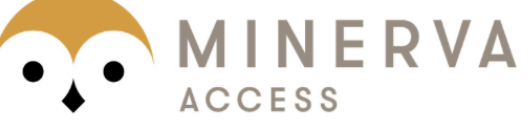

A gateway to Melbourne's research publications

Minerva Access is the Institutional Repository of The University of Melbourne

\section{Author/s:}

Kellert, L;Kloss, M;Pezzini, A;Debette, S;Leys, D;Caso, V;Thijs, VN;Bersano, A;Touze,

E;Tatlisumak, T;Traenka, C;Lyrer, PA;Engelter, ST;Metso, TM;Grond-Ginsbach, C

Title:

Prognostic significance of pulsatile tinnitus in cervical artery dissection

Date:

2016-07-01

\section{Citation:}

Kellert, L., Kloss, M., Pezzini, A., Debette, S., Leys, D., Caso, V., Thijs, V. N., Bersano, A., Touze, E., Tatlisumak, T., Traenka, C., Lyrer, P. A., Engelter, S. T., Metso, T. M. \& Grond-Ginsbach, C. (2016). Prognostic significance of pulsatile tinnitus in cervical artery dissection. EUROPEAN JOURNAL OF NEUROLOGY, 23 (7), pp.1183-1187. https:// doi.org/10.1111/ene.13031.

Persistent Link:

http://hdl.handle.net/11343/291214 